Article

\title{
Theoretical Study on Cryogen Spray Cooling in Laser Treatment of Ota's Nevus: Comparison and Optimization of R134a, R404A and R32
}

\author{
Jiameng Tian ${ }^{1,2}$, Bin Chen ${ }^{1, *}$, Zhifu Zhou ${ }^{1}$ and Dong $\mathrm{Li}^{1}$ \\ 1 State Key Laboratory of Multiphase Flow in Power Engineering, Xi'an Jiaotong University, \\ Xi'an 710049, China; tianjiameng@ujs.edu.cn (J.T.); zfzhou@mail.xjtu.edu.cn (Z.Z.); \\ lidong@mail.xjtu.edu.cn (D.L.) \\ 2 School of Energy and Power Engineering, Jiangsu University, Zhenjiang 212013, China \\ * Correspondence: chenbin@xjtu.edu.cn
}

Received: 26 September 2020; Accepted: 27 October 2020; Published: 28 October 2020

check for updates

\begin{abstract}
Cryogen spray cooling (CSC) could be applied clinically for the laser therapy of Ota's nevus, a dermal hyperplastic pigmented disease with a morbidity rate of $0.1-0.6 \%$ in the Asian population. An accurate, efficient, complete simulation system that considers the entire spray cooling process, including cryogen flow in the tube nozzle, spray dynamics and internal phase change heat transfer (cold injury) in skin tissue, was established to determine suitable cryogen and cooling parameters. The optimum spray distances for R134a, R404A and R32 were determined to be 66.0, 43.1 and $22.5 \mathrm{~mm}$, respectively. The corresponding maximum surface heat fluxes were $363.5,459.9$, and $603.6 \mathrm{~kW} \cdot \mathrm{m}^{-2}$, respectively. The maximum surface heat flux of R32 with small spray distance was 1.66 times as large as that of R134a, indicating the potentially good cooling performance and precise targeted cooling of R32 during the laser therapy of Ota's nevus. The cooling durations that caused cold injury of skin tissue were 2.3, 1.4, and $1.1 \mathrm{~s}$ for R134a, R404A, and R32, respectively. The interval between CSC and laser irradiation was optimized to 90-162 ms for R134a, R404A and R32, in consideration of the cooling effect, depth, uniformity, and risk of cold injury.
\end{abstract}

Keywords: cryogen spray cooling; nevus of Ota; laser therapy; cold injury; bio-heat transfer

\section{Introduction}

Ota's nevus is a dermal disorder of hyperpigmentation with a morbidity rate of $0.1 \%-0.6 \%$ in the Asian population [1]. It mostly distributes on the face and neck, and is caused by the abnormal migration of primitive melanocytes in skin tissue at the embryonic stage. As shown in Figure 1, the human skin is a multi-layered structure comprised of the epidermis, dermis and subcutaneous tissue (from the outermost to the innermost layer). Normal melanin with a diameter of $0.1-0.2 \mu \mathrm{m}$ is buried in the epidermal layer, and its content determines skin color [2]. Melanin lesions are buried in the dermis layer and can be seen as irregular spindles with diameters of $0.25-0.65 \mu \mathrm{m}$ on histopathologic slides [3]. Laser surgery with $532 \mathrm{~nm} / 1064 \mathrm{~nm}$ Nd:YAG and $755 \mathrm{~nm}$ alexandrite lasers is implemented in clinical settings due to selective photothermolysis [4]. Laser heating can thermally damage melanin lesions, accompanied with the explosive vaporization of melanosome. The surrounding tissues survive maximally. However, the high laser absorption of epidermal normal melanin often causes adverse side effects, such as epidermal thermal injury, hypopigmentation and bleeding [5]. Effective skin cooling technologies must be developed urgently to solve these problems. 


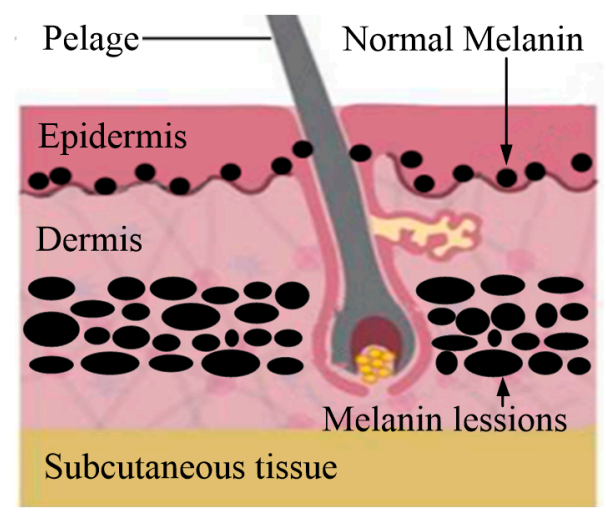

Figure 1. Schematic of the skin structure of Ota's nevus.

Cryogen spray cooling (CSC) has a high cooling capacity and spatial and temporal selectivity. It allows for the rapid evaporation of the liquid film (completely evaporation time $\leq 30 \mathrm{~ms}$ [6]) on the skin surface due to the large temperature difference between liquid film and environmental air, and is nontoxic to the human body. Thus, CSC can facilitate the pre-cooling of the epidermis before laser irradiation. CSC has been successfully used in the laser therapy of port-wine stain (PWS) birthmarks to avoid thermal injury on the epidermis caused by the competitive laser absorption between epidermal melanin and dermal blood. However, the potential application of CSC in the laser therapy of Ota's nevus has not yet been investigated. The CSC parameters used in PWS cannot be directly applied to Ota's nevus owing to the large differences in tissue composition and structure, as well as the special requirement in terms of larger cooling capacity. The potential clinical application of CSC in the laser therapy of Ota's nevus aims to avoid the competitive laser absorption between epidermal and dermal melanin, which cannot be realized by changing the laser wavelength. The selection of cryogen for safe and clinical application should follow these rules [7]: (1) high thermal conductivity for rapid heat removal from skin tissue; (2) low boiling point and high latent heat for enough cooling and the fast evaporation of the liquid film on the skin surface; (3) no adverse health effects or danger to the human body, as well as environmental effects. In the laser treatment of PWS, R134a with a normal boiling point $\left(T_{b}\right)$ of $-26.1^{\circ} \mathrm{C}$ was approved by the U.S. Food and Drug Administration (FDA) for clinical utilization, but its insufficient cooling capacity is not applicable for darkly pigmented human skin [8]. R404A with a low $T_{b}\left(-46.5^{\circ} \mathrm{C}\right)$ may be a substitute for R134a, because it produces a powerful cooling effect with an increment of $17.8 \%$ in surface heat flux $[9,10]$. The nontoxicity and safety in the human body of R404A were approved by the American Society of Heating Refrigerating and Airconditioning Engineers (ASHRAE) [11]. Furthermore, the histological observation investigation conducted by Dai et al. [8] demonstrated that the utilization of R404A with spurt durations up to $300 \mathrm{~ms}$ did not produce obvious morphological changes to dark-pigmented human skin. For R32, animal studies indicated that the acute inhalation toxicity is very low and no adverse human health effects were reported, as documented by the International Occupational Safety and Health Information Centre (CIS) [12]. Although R32 is flammable, the local R32 vapor concentration is around $0.24-4.76 \mathrm{~g} / \mathrm{m}^{3}$ in a supposed space $1 \mathrm{~m}^{3}$, under the clinical spurt duration (5-100 ms) [13] and mass flow rate $(47.63 \mathrm{~g} / \mathrm{s})$ parameters, which is far less than the lower flammability limit (equated mass concentration, $306 \mathrm{~g} / \mathrm{m}^{3}$ ) [14], indicating the safety in terms of flammability. Moreover, the suction cup joined with a vacuum hand pump [15] can be implemented to collect the cryogen vapor to ensure its safe application for the human body. R134a and R404A have zero ozone-depleting potential, but their extremely high global warming potentials (GWP; 1430 for R134a, 3850 for R404A) necessitate the substitution of a new cryogen. In the laser surgery of PWS, most of the laser energy is absorbed by hemoglobin, whereas a small amount is absorbed by epidermal melanin; this can be realized by selecting an appropriate laser wavelength. However, the laser absorption is similar between normal epidermal melanin $\left(\mu_{a}=750-800 \mathrm{~m}^{-1}\right.$, $\lambda=450-800 \mathrm{~nm}$ [16] $)$ and abnormal dermal melanin $\left(\mu_{a}=700-800 \mathrm{~m}^{-1}, \lambda=450-1050 \mathrm{~nm}\right.$ [17]) in 
Ota's nevus, resulting in a high temperature increase in the epidermal melanin and surrounding tissue. Therefore, a large cooling capacity is required for the CSC-assisted laser therapy of Ota's nevus. R32 with a low boiling point $\left(-51.9^{\circ} \mathrm{C}\right)$ and low GWP (675) may be used as a potential cryogen in the laser therapy of Ota's nevus. However, little work has focused on R32's spray dynamics, cooling effect and parameter optimization for practical applications. Although the spray distances for R134a and R404A spray cooling have been optimized for the laser therapy of PWS [18], the spray distance and other parameters should be re-optimized for Ota's nevus due to the large difference in tissue composition and structure.

CSC is a complicated process that merges the gas-liquid flow in the capillary tube, the atomization, evaporation and breakup of spray droplets, the boiling heat transfer on the skin surface, and the phase-change heat transfer (cold injury) inside bio-tissue. Experimental investigations cannot effectively reveal spray cooling mechanisms, but numerical simulation is a powerful tool for this task. Nilpueng and Wongwises [19] proposed the homogeneous flow model to simulate the internal cryogen flow in a straight-tube nozzle by dividing the flow state into subcooled, metastable, and two-phase regions. Many theoretical models targeted at spray dynamics have been developed to simulate the atomization, evaporation and breakup of spray droplets. For example, Zeng and Lee [20] proposed an atomization model assuming that the droplet primary breakup is affected by air drag force and bubble growth on the droplet surface. Witlox et al. [21,22] established the relationship between droplet diameter and superheat degree under mechanical transition and atomization by using a piecewise linear function. Other researchers focused on the initial droplet diameter distribution [23]. Witlox et al. [21] improved the Rosin-Rammler distribution model to simulate spray dynamics and found that after atomization, evaporation and secondary breakup occur when a droplet flies. Ranz and Marshall [24] identified the classical convective heat and mass transfer correlation for water droplet evaporation. Afterward, Spalding [21], R-Y [24] and N-G [25] models were developed for consideration of the blowing effect. Zhou et al. [26] proposed an N-G-R-M model by comprehensively considering the convection and blowing effect to predict droplet evaporation with different evaporation rates accurately. Droplets break up due to the shear force of gas. Four available droplet breakup models, namely, Taylor analogy breakup (TAB) [27], wave breakup [28], Kelvin-Helmholtz [29] and stochastic secondary droplet (SSD) [30], can be used to simulate droplet breakup under different Weber numbers. Aiming at the simulation of bio-tissue phase-change heat transfer upon CSC, Li et al. [31] also constructed a multi-scale heat transfer model based on cellular frostbite theory to simulate cell dehydration and intracellular ice formation. This model has been proven successful in predicting safe spray durations of CSC to prevent cold injury of skin tissue. However, little work has focused on CSC for the laser therapy of Ota's nevus.

The aforementioned investigations only focused on a single physical process during spray cooling. In the present work, an accurate, efficient, complete simulation system that considers the entire process of cryogen spray was constructed by considering the processes of gas-liquid flow through a nozzle tube, the atomization, evaporation and breakup of spray droplets, and phase-change heat transfer (cold injury) inside bio-tissue, using well established mathematical models for the literature. Besides, the coupling of the heat transfer model on the skin surface constructed a bridge between the micro-spray droplet characteristics and surface boiling heat transfer, which can prevent the direct simulation of the complicated droplet impact cooling process, thus highly reducing the computation load. With the complete simulation system, the simulation results were compared with experiments in terms of droplet temperature and diameter, as well as the surface temperature of skin tissue. Then, the spray characteristics of R134a, R404A and R32 spray cooling were compared. Afterward, the spray distances of CSC with three cryogens were optimized to determine the best cooling capability and investigate the potential application of the new cryogen R32 in clinics. In addition, the interval between CSC and laser irradiation was determined by comprehensively considering cooling performance, cooling depth, cooling uniformity and risk of cold injury to provide theoretical guidance for the safe and precise clinical application of CSC in the laser treatment of Ota's nevus. 


\section{Mathematical Modeling for Cryogen Spray Cooling}

To establish the complete simulation system, a 1D homogenous flow model was employed to solve the two-phase cryogen flow in a tube [19]. The discrete phase model (DPM) was employed to simulate spray atomization, droplet evaporation and breakup under the Euler-Lagrange framework. Cell dehydration and intracellular ice formation under CSC were also simulated using the multi-scale bio-tissue heat transfer model based on cellular frostbite theory [31]. Given that the present study mainly concerns the simulation of the spray field and heat transfer inside skin tissue, the details of the 1D homogenous flow model [19] are not discussed in this paper.

\subsection{Discrete Phase Model for Spray Dynamics}

\subsubsection{Droplet Motion, Breakup and Evaporation}

The DPM method tracks individual droplet motion under the Lagrangian framework to simulate droplet motion, breakup and evaporation. In consideration of the effects of gravity and gas drag force on a discrete droplet, the motion of the droplet can be calculated by

$$
\frac{d \mathbf{u}_{d}}{d t}=f_{D}\left(\mathbf{u}_{a}-\mathbf{u}_{d}\right)+\frac{\mathbf{g}\left(\rho_{d}-\rho_{a}\right)}{\rho_{d}}
$$

where $\mathbf{u}_{d}$ and $\mathbf{u}_{a}$ are the velocities of the droplet and ambient gas, $\mathbf{g}$ is the acceleration of gravity, $\rho_{d}$ and $\rho_{a}$ are the densities of the droplet and ambient gas, nad $f_{D}\left(\mathbf{u}_{a}-\mathbf{u}_{d}\right)$ is the drag force of the droplet per unit mass from surrounding gas. $f_{D}$ is the drag force coefficient introduced in Morsi and Alexander's work [32].

Violent flashing atomization often occurs at the nozzle exit during CSC, because of the sudden release of high-pressure cryogen spraying into a low-pressure environment. It is very difficult to directly simulate such a complicated flash, including bubble formation on the droplet surface and the droplet breakup induced by the bubble explosion, coupled with the phase-change heat and mass transfer. Furthermore, the present work mainly focuses on the fully-developed spay after flashing atomization at the nozzle exit, because the clinical spray distance is often selected to be larger than $10 \mathrm{~mm}$ to obtain the good cooling performance. Thus, a piecewise linear model proposed by Witlox et al. [22] concerning the effect of superheat degree on different atomization forms (mechanical, transition and flashing atomization) was adopted in the present simulation to obtain the droplet diameter distribution after flashing atomization occurs. The later model validation indicates the rationality of such treatment, which also avoids the complicated simulation of flash. The droplet temperature after flashing atomization is assumed to be the boiling point in an atmospheric environment. The stochastic secondary droplet (SSD) model [30] was applied to simulate droplet breakup in the fully-developed spray induced by the gaseous shear force, due to the model's advantage of small computation load. In the SSD model, the breakup of numerous droplets with a high Weber number is regarded as a discrete random event, in which the breakup degree is related to the size of the parent droplet.

For flashing spray, the cryogen droplet temperature decreased to the boiling point at the nozzle outlet. Droplet evaporation dominated during droplet flight with a high velocity in the fully-developed spray. The convection/diffusion controlled model proposed by Miller et al. [33,34] was used to calculate the mass transfer during droplet evaporation, as follows:

$$
\frac{d m_{d}}{d t}=k_{c} A_{d} \rho_{d} \ln \left(1+B_{m}\right)
$$

where $m_{d}$ and $A_{d}$ denote droplet mass and surface area. $B_{m}$ is the Spalding mass transfer number. The mass transfer coefficient, $k_{c}$, was computed by the N-G-R-M model that considers the convective and blowing effect of air at the droplet interface, proposed by Zhou et al. [26]. The heat transfer between droplet and ambient gas was simulated with the lumped parameter method on the basis 
of the assumption of uniform density and temperature inside the droplet. The energy conservation equation is

$$
m_{d} c_{p, d} \frac{d T_{d}}{d t}=h A_{d}\left(T_{a}-T_{d}\right)-\frac{d m_{d}}{d t} h_{f g}+A_{d} \varepsilon_{d} \sigma\left(T_{r}^{4}-T_{d}^{4}\right)
$$

where $T_{d}$ and $T_{a}$ are the droplet and gas temperature, $c_{p, d}$ and $h_{f g}$ are the specific heat and latent heat of the droplet, and $\varepsilon_{d}$ and $T_{r}$ are the spectral emissivity and radiation temperature of the droplet. $\varepsilon_{d}$ is assumed to be 0.96 , which is the same as that of water because of the similar optical properties, since there are no measured data for cryogens. $\sigma$ is the Stefan-Boltzmann constant, i.e., $\sigma=5.67 \times 10^{-8} \mathrm{~W} \cdot \mathrm{m}^{-2} \cdot \mathrm{K}^{-4}$. The key parameter for droplet evaporation, i.e., convective heat transfer coefficient $(h)$, can be determined by the Nusselt number correlation proposed by Sergei $S$. Sazhin [34],

$$
N u=\frac{\ln \left(1+B_{t}\right)}{B_{t}}\left(2+0.552 R e^{1 / 2}+\operatorname{Pr}^{1 / 3}\right)
$$

where $N u=h d / \lambda_{a}, \operatorname{Re}=\rho_{d} d\left|\mathbf{u}_{d}-\mathbf{u}_{a}\right| / \eta, P r=c_{p, d} \eta / \lambda_{a}, B_{t}=c_{p, a}\left(T_{a}-T_{d}\right) / h_{f g} . \eta$ and $h_{f g}$ are the viscosity and latent heat of droplet. $\lambda_{a}$ and $c_{p, a}$ are the heat conductivity coefficient and specific heat of gas. The Nusselt number correlation (Equation (4)) was obtained by Sergei S. Sazhin [34] using dimensional analysis, and is applicable to the convective heat transfer for moving droplet evaporation with high velocity, such as cryogen droplet evaporation during CSC. Its accuracy has been validated by Zhou et al. [26]. However, the temperature-dependent thermal properties of the droplet and the surrounding air should be used to accurately implement the Nusselt number correlation in the current study.

\subsubsection{Governing Equations for Continuous Gas}

The simulation of the gas phase was conducted under the Eulerian framework by considering mass, momentum and energy conservation. The mass conservation equation is expressed as

$$
\frac{\rho}{\partial t}+\nabla \cdot(\rho \mathbf{u})=S_{m}
$$

$S_{m}$ is the mass source term induced by droplet evaporation. The momentum conservation equation can be obtained by solving the Navier-Stokes equation

$$
\frac{\partial}{\partial t}(\rho \mathbf{u})+\nabla \cdot(\rho \mathbf{u u})=-\nabla p+\nabla \cdot \overline{\bar{\tau}}+\rho g+\mathbf{F}
$$

where $\mathbf{F}$ is the momentum source term described by the change of droplet momentum in the control volume. $p$ is the pressure, and $\overline{\bar{\tau}}$ is the tensor of stress. The energy conservation equation is

$$
\frac{\partial}{\partial t}(\rho E)+\nabla \cdot(\mathbf{u}(\rho E+p))=\nabla \cdot\left(k_{e f f} \nabla T_{a}-\sum_{i} h_{i} J_{i}+(\overline{\bar{\tau}} \cdot \mathbf{u})\right)+\rho g+S_{h}
$$

where $k_{\text {eff }}$ pertains to effective thermal conductivity, and $S_{h}$ is the energy source term. $h_{i}$ and $J_{i}$ are the enthalpy and diffusion rate of the $i$ th component in the gas phase, respectively. The two-way coupling of mass, momentum, and energy transfer between discrete droplets and the continuous gas were established with the source terms in Equations (5)-(7).

\subsection{Multi-Scale Heat Transfer Model for Skin Tissue Frostbite}

When the tissue cell temperature is below $0{ }^{\circ} \mathrm{C}$, water in the cell starts to freeze. The cell state can be regarded as unfrozen, partially frozen, or completely frozen. In the partially frozen state, extracellular ice forms first, yielding to the water transported on the cell surface because of the concentration difference. The cell death induced by intracellular ice formation (IIF) occurs with a sufficiently high cooling rate. Meanwhile, if the cooling rate is relatively slow, cell dehydration is induced because of 
water transport on the cell surface. Differing between traditional engineering materials, the macro-scale heat transfer and the micro-scale cellular-level biophysical events (intracellular ice formation and cell dehydration) must be considered simultaneously when solving the heat and mass transfer dynamics to evaluate the cold injury of skin tissue under CSC, and this task can be executed with the multi-scale heat transfer model developed by Li et al. [31]. Macro-scale heat transfer equations were implemented to calculate the temperature distribution in the skin tissue, considering the heat source term induced by intracellular ice formation and cell dehydration,

$$
\rho_{j} c_{j} \frac{\partial T}{\partial t}=\nabla \cdot\left(\lambda_{j} \nabla T\right)+a\left[(1-\mathrm{PIIF}) \frac{2 \pi R_{e c} \rho L}{\Delta x^{2}} \frac{d R_{e c}}{d t}+\frac{\left(V_{c}-V_{n s}\right) \rho L}{\Delta x^{3}} \frac{d \mathrm{PIIF}}{d t}\right]
$$

where $\rho, c$ and $\lambda$ are the density, specific heat and heat conduction of tissue coefficient. The subscript $j$ denotes the unfrozen $(u f)$, completely frozen $(c f)$ and partially frozen states $(p f)$, respectively. $V_{c}$ and $V_{n s}$ are the cell volume and total volume of Krogh unit. PIIF is the probability of IIF, and $L$ is the latent heat of water. $\Delta x$ and $R_{e c}$ are the Krogh unit dimension and equivalent radius of the extra-cellular space. $a$ equals 0 for the unfrozen and completely frozen states, and 1 for the partially frozen sate.

The micro-scale mass transfer equation can be implemented in the Krogh unit that represents a specific space with a similar tissue structure, containing certain numbers of cells and surrounded by interstitial fluid. The mass transfer inside the Krogh unit was considered by solving the radius change of the cylindrical extracellular space because of the water transport on the cell surface. The ice formation was coupled with the macro-heat transfer equation as the latent heat source term. PIIF is calculated by the following equation [35],

$$
\mathrm{PIIF}=1+\exp \left[\int_{T_{f}}^{T} A \Omega\left(\frac{T}{T_{f, 0}}\right)^{1 / 2} \frac{\eta_{c, 0}}{\eta_{c}} \frac{A_{c}}{A_{c, 0}} \exp \left(\frac{-k_{c}\left(T / T_{f, 0}\right)^{1 / 4}}{\left(T-T_{f}\right)^{2} T^{3}}\right) d t\right]
$$

where $T_{f}$ is the water freezing point, and $A_{c}$ is the valid superficial cell area for water transport. $k_{c}$ and $\Omega$ are the thermodynamic and kinetic parameter for crystal nucleation on the cell surface. $\eta_{c}$ is the intracellular solution viscosity, determined by Bischof and Rubinsky's work [36]. By solving the multi-scale heat transfer equations, the temperature distribution of skin tissue, the dynamic change in $R_{e c}$, and the PIIF can be obtained and used to evaluate cold injury during CSC. Cold injury occurs when the PIIF is 1 or $R_{e c}$ reaches its maximum value $R_{e c, \max }$, which is determined by the equivalent radius of Krogh unit volume without the water component [36].

\subsection{Simulation Conditions and Model Validation}

Figure 2 indicates that the simulation considered a 3D axisymmetric cylinder domain with a radius of $25 \mathrm{~mm}$ and a height of $103 \mathrm{~mm}$, consisting of spray $\left(Z_{s}=100 \mathrm{~mm}\right)$ and skin tissue $\left(Z_{t}=3 \mathrm{~mm}\right)$ domains. The origin of the coordinates was located at the nozzle exit, and the cryogen was spurted onto the skin surface vertically. In accordance with the histological anatomy of Ota's nevus [37], the skin tissue domain consisted of four planar layers, namely, the epidermis, dermis without melanin, dermis with melanin, and dermis without the melanin layer. The Krogh unit with a dimension of $(\Delta x \times \Delta x \times \Delta x)$ was used to represent the specific space containing certain numbers of cells and surrounding interstitial fluid $(\Delta x=22 \mu \mathrm{m})$, determined by the average distance between two adjacent sinusoids in the scanning electron micrographs of the tissue [36]. In accordance with the Asian skin structure, the epidermis thickness was assumed to be $60 \mu \mathrm{m}$. The total thickness of the dermis layer was $2940 \mu \mathrm{m}$. Melanin volume fractions of $15 \%$ and $35 \%$ were uniformly distributed in the epidermis and dermis melanin layers, and no melanin existed in the other layers. 


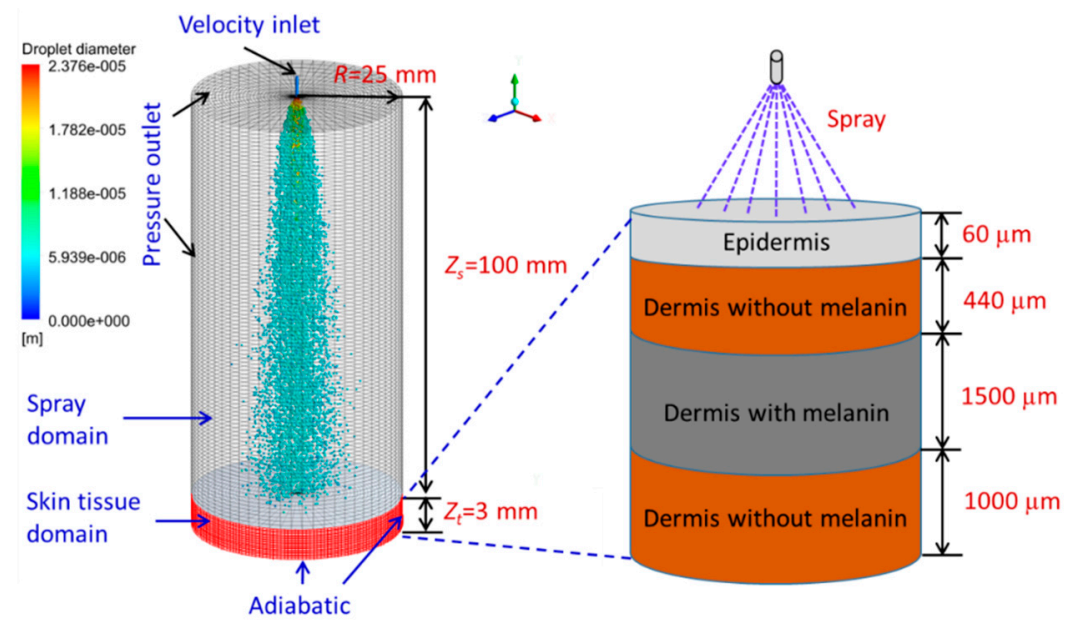

Figure 2. Computational domain and boundary conditions for simulation of cryogen spray cooling.

The experimental investigation of heat transfer performance during R404A spray cooling by Zhou et al. [38] indicated that a spurt duration longer than $50 \mathrm{~ms}$ has an insignificant effect on cooling capacity. As such, a spurt duration of $50 \mathrm{~ms}$ was selected in the current work. Three cryogens of R134a, R404A and R32 were compared in the present work. The physical properties of three cryogens at $25^{\circ} \mathrm{C}$ and $1 \mathrm{~atm}$ are compared in Table 1 , and the thermal properties of the skin components are documented in Table 2.

Table 1. Physical properties of R134a, R404A and R32 (25 $\left.{ }^{\circ} \mathrm{C}, 1 \mathrm{~atm}\right)$.

\begin{tabular}{|c|c|c|c|c|c|c|c|c|}
\hline Cryogens & $\begin{array}{c}\rho_{d} \\
\left(\mathrm{~kg} / \mathrm{m}^{3}\right)\end{array}$ & $\begin{array}{c}c_{p, d} \\
(\mathrm{~J} / \mathrm{kg} \cdot \mathrm{K})\end{array}$ & $\begin{array}{c}\lambda_{d} \\
(W / \mathrm{m} \cdot \mathrm{K})\end{array}$ & $\begin{array}{c}T_{b} \\
\left({ }^{\circ} \mathrm{C}\right)\end{array}$ & $\begin{array}{c}p_{\text {sat }} \\
(\mathrm{MPa})\end{array}$ & $\begin{array}{c}\sigma \\
(\mathrm{N} / \mathrm{m})\end{array}$ & $\begin{array}{c}\eta \\
(\mathbf{P a} \cdot \mathbf{s})\end{array}$ & $\begin{array}{c}h_{f g} \\
(\mathrm{~J} / \mathrm{kg})\end{array}$ \\
\hline R134a & 1206.7 & 1424.6 & 0.0811 & -26.1 & 0.67 & 0.0081 & 0.00019 & 216,000 \\
\hline R404A & 1044.1 & 1542.3 & 0.0646 & -46.5 & 1.25 & 0.0046 & 0.00013 & 230,260 \\
\hline $\mathrm{R} 32$ & 961.0 & 1936.7 & 0.1259 & -51.9 & 1.69 & 0.0068 & 0.00011 & 270,910 \\
\hline
\end{tabular}

Table 2. Thermal properties of skin components [39].

\begin{tabular}{cccc}
\hline Properties & States & Epidermis & Dermis \\
\hline \multirow{2}{*}{$\rho\left(\mathrm{kg} \cdot \mathrm{m}^{-3}\right)$} & Unfrozen & 1120 & 1090 \\
& Completely frozen & 1120 & 921 \\
\hline \multirow{2}{*}{$c\left(\mathrm{~J} \cdot \mathrm{kg}^{-1} \cdot \mathrm{K}^{-1}\right)$} & Unfrozen & 3200 & 3500 \\
& Completely frozen & 3200 & 1230 \\
\multirow{2}{*}{$\lambda\left(\mathrm{W} \cdot \mathrm{m}^{-1} \cdot \mathrm{K}^{-1}\right)$} & Unfrozen & 0.34 & 0.41 \\
& Completely frozen & 0.34 & 2.25 \\
\hline
\end{tabular}

The constant flow velocity boundary condition was implemented at the nozzle inlet. The pressure outlet boundary was employed at the surface of the spray domain. Direct simulation considering the complex processes of spray droplet impact cooling, heat transfer inside the liquid film, and interactions between droplet and thin liquid film on the skin surface is very difficult. Alternatively, the heat transfer model for the skin surface $\left(Z_{t}=0\right)$ was applied to simulate the integrated cooling effect during CSC, as follows:

$$
-\left.\lambda \frac{\partial T}{\partial z}\right|_{Z_{t}=0}=q(\phi, R, t)
$$


The surface heat flux was calculated with the general correlation proposed by Tian et al. [10] as follows:

$$
\frac{B i^{*}}{B i_{\max }^{*}}=\left\{\begin{array}{cc}
\frac{F o_{\mathrm{s}}}{F o_{\mathrm{s}} \max } & 0 \leq \frac{F o_{\mathrm{s}}}{F o_{\mathrm{s}} \text { max }} \leq 1 \\
1.265 \mathrm{e}^{\left(-\frac{F o_{\mathrm{s}}}{1.9 F o_{\mathrm{s}, \max }}\right)}+0.25 & 1<\frac{F o_{\mathrm{s}}}{F o_{\mathrm{s}, \max }} \leq 14
\end{array}\right.
$$

where $B i^{*}$ is the spray Biot number that measures the relationship between surface convective heat transfer resistance and internal thermal resistance of the skin during CSC [10] $\left(B i^{*}=h^{*} \delta / \lambda\right.$, $\left.h^{*}=q /\left(T_{0}-T_{d}\right)\right) . T_{0}, \delta$ and $\lambda$ denote the initial temperature, thickness, and heat conductivity coefficient, respectively. $T_{d}$ is the spray droplet temperature $\left(F o_{\mathrm{s}}=a t / \delta^{2}\right) . a$ is the thermal diffusivity.

Note that the heat transfer inside the skin tissue is mainly the conduction of cooling capacity under CSC, and the blood perfusion can be ignored because of the short spurt duration of $50 \mathrm{~ms}$. Furthermore, the heat transfer at the domain boundaries inside the skin can be ignored, since the computation lengths in the axial and radial direction are more than five times as large as the cooling depth $\left(Z_{t, d} \sim 300 \mu \mathrm{m}\right)$ and cooling radius $\left(r_{s} \sim 5 \mathrm{~mm}\right.$ at clinical spray distance). Thus, the adiabatic boundary condition was implemented for the other sides of the skin tissue domain shown in Figure 2. The initial temperature of the skin tissue and the air in the spray domain were assumed to be $37{ }^{\circ} \mathrm{C}$ and $25^{\circ} \mathrm{C}$, respectively. The initial temperatures of the cryogens were assumed to be their boiling points $\left(T_{b}\right)$, as shown in Table 1.

The flowchart of simulation was drawn in Figure 3, wherein the complete simulation system consists of two parts, the spray field and the phase-change heat transfer inside the skin tissue. The solution procedure includes the following steps:

(1) Calculate the initial spray parameters (droplet initial temperature, velocity, diameter and distribution) via the 1D homogenous flow model [19] and the piecewise linear model [22];

(2) Compute the droplet velocity, diameter and temperature via the droplet movement, breakup and evaporation models [30,32-34], under the Lagrangian framework using Equations (1)-(4);

(3) Calculate the gas concentration, velocity and temperature distribution by solving the mass, momentum and energy governing equations (Equations (5)-(7)) under the Eulerian framework with the implicit time scheme and SIMPLE algorithm;

(4) Calculate the heat and mass transfer between the droplet and the surrounding gas using the two-way coupling method with the source terms $S_{m}, \mathbf{F}$ and $S_{h}$;

(5) Calculate the heat flux on the skin surface with the surface heat transfer model (Equations (10) and (11)) [10];

(6) Compute the temperature distribution by solving the macro-scale bio-heat conduction equation (Equation (8)) [31] coupled with the latent heat $(L)$ released from the cellular water freezing;

(7) Compute the probability of intracellular ice formation (PIIF) and the radius of the cylindrical extra-cellular space $\left(R_{e c}\right)$ by solving the micro-scale mass transfer equation (Equation (9)) [35].

Since the number of spray droplets decreases along the radial direction, the uniform radiant-type tetrahedral mesh was used to discretize the computational domain. Two sets of grid sizes were employed for the spray field and skin tissue because of the large differences in domain size. The mesh sizes with an azimuth angle $(\Delta \varnothing)$, radial size $(\Delta r)$ and cell height $(\Delta z)$ of $9^{\circ} \times 0.8 \mathrm{~mm} \times 2 \mathrm{~mm}$, $6^{\circ} \times 0.8 \mathrm{~mm} \times 1 \mathrm{~mm}$ and $3^{\circ} \times 0.4 \mathrm{~mm} \times 1 \mathrm{~mm}$, respectively, were used to test the mesh sensitivity for the spray domain. Figure 4 illustrates that no apparent distinction in droplet diameter distribution can be seen when further refining the grid from $6^{\circ} \times 0.8 \mathrm{~mm} \times 1 \mathrm{~mm}$ to $3^{\circ} \times 0.4 \mathrm{~mm} \times 1 \mathrm{~mm}$. Thus, the $6^{\circ} \times 0.8 \mathrm{~mm} \times 1 \mathrm{~mm}$ grid was selected for the spray domain. 


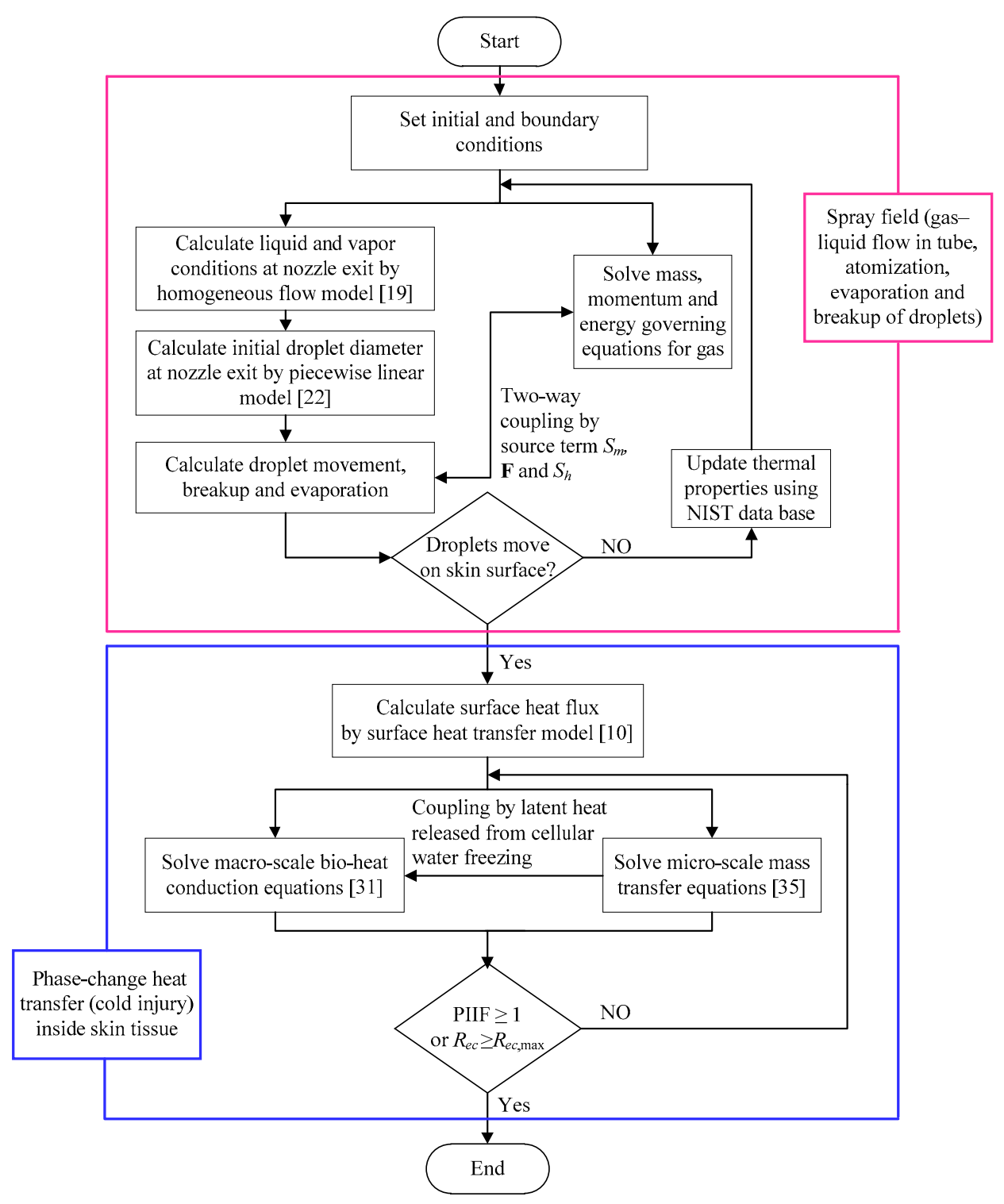

Figure 3. Flowchart of present simulation.

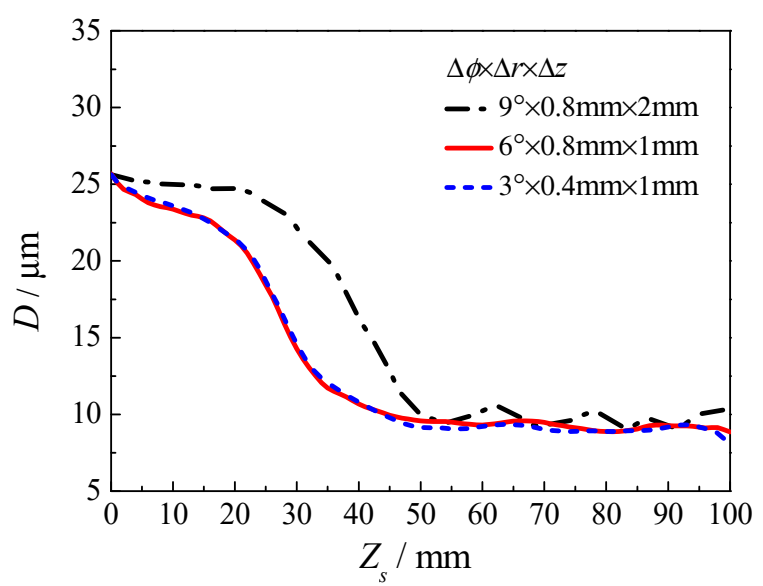

Figure 4. Axial droplet diameter distributions under different mesh sizes.

As shown in Figure 5, no significant distinction in tissue temperature can be seen with cell size smaller than $6^{\circ} \times 80 \mu \mathrm{m} \times 20 \mu \mathrm{m}$. Thus, the cell size for skin tissue can be determined to be 
$6^{\circ} \times 80 \mu \mathrm{m} \times 20 \mu \mathrm{m}$. The cell number is 5,625,000 $(60 \times 625 \times 150)$. The cell size of $6^{\circ} \times 80 \mu \mathrm{m} \times 20 \mu \mathrm{m}$ is small enough to discretize the computational domain at different skin layers.

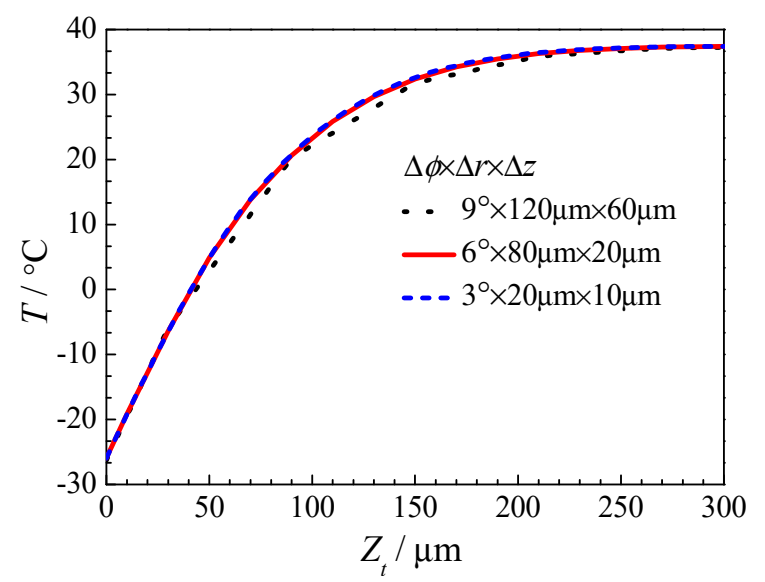

Figure 5. Axial temperature in skin tissue at different grid sizes.

Figure 6 shows the comparison of axial temperatures in the skin tissue with uniform $\left(6^{\circ} \times 80 \mu \mathrm{m} \times 20 \mu \mathrm{m}\right)$ and nonuniform mesh systems, which were comprised of four different grid subsystems with identical $\Delta \varnothing$ and $\Delta r$, but different cell heights $\Delta z$ of $3 \mu \mathrm{m}, 5 \mu \mathrm{m}, 10 \mu \mathrm{m}$ and $20 \mu \mathrm{m}$ for the epidermis, dermis without melanin, dermis with melanin, and dermis without melanin layers, respectively. Figure 6 indicates that no significant distinction in axial tissue temperature was found using the uniform versus nonuniform mesh systems. To save computational load, the uniform mesh system was employed for the current simulation.

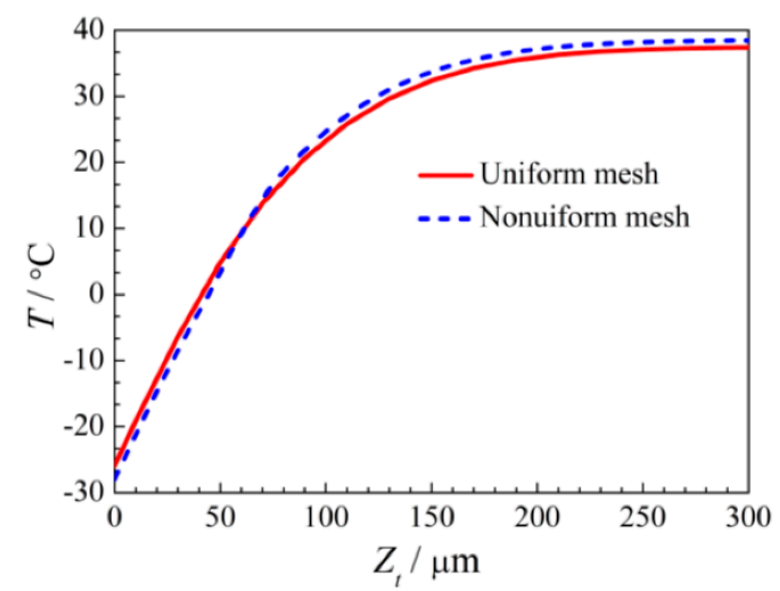

Figure 6. Axial temperature in skin tissue with uniform and nonuniform mesh system.

R134a spray cooling was first simulated to validate the accuracy of the present model. A straight tube nozzle (inner diameter, $1.0 \mathrm{~mm}$ and length, $60 \mathrm{~mm}$ ) was implemented to produce spray droplets. The simulated spray pattern (Figure 7a) was drawn in a 2D diagram to validate the accuracy of the present algorithm.

Figure 7 illustrates that good agreement in the spray pattern was found between the experiment of Zhou et al. [40] and the simulated results of the present model. The simulated droplet temperature and diameter, and the surface temperature of the skin tissue, match well with those in the experiment, proving the accuracy of the present model (Figure 8). 


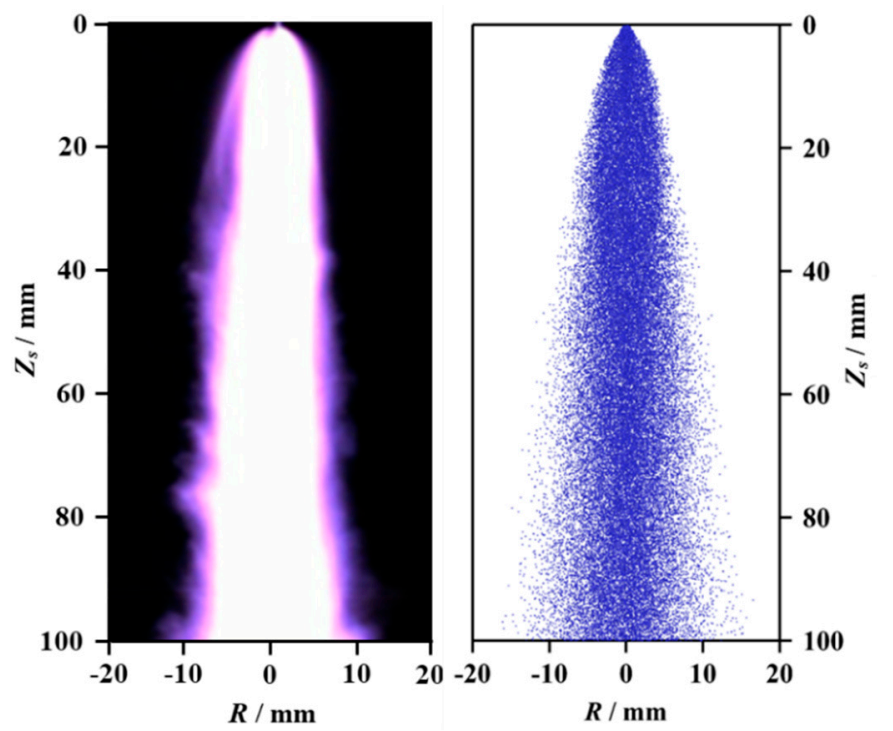

(a)

(b)

Figure 7. Comparison of spray patterns in the (a) experiment [40] and (b) simulation.

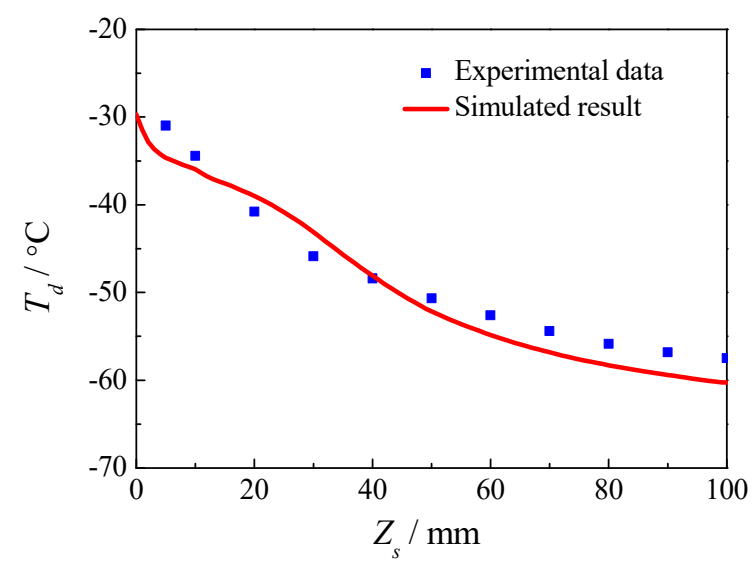

(a)

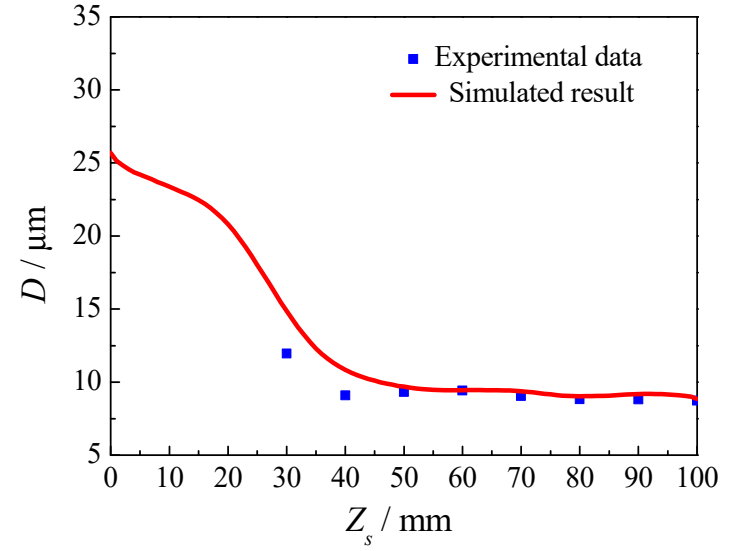

(b)

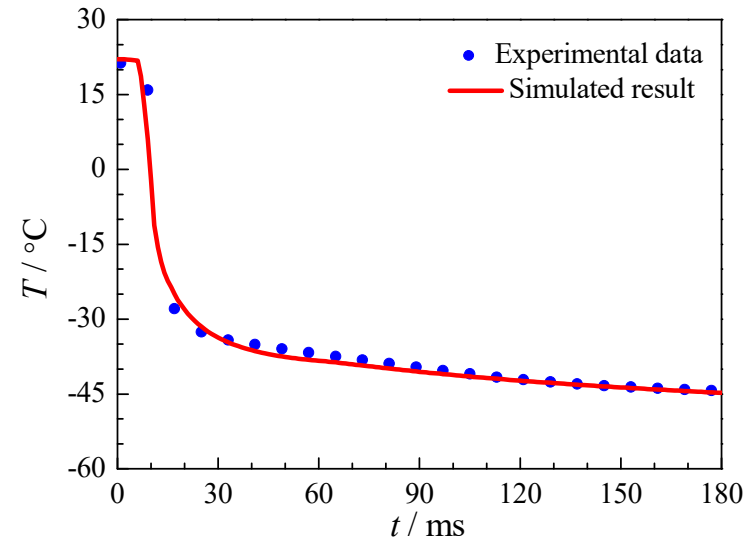

(c)

Figure 8. Comparison of (a) droplet temperature, (b) diameter and (c) surface temperature of skin tissue in the experiment [40] and simulation.

As shown in Figure 9, most of relative errors in the simulated results were less than $6 \%$, which further validates the accuracy of the present model. The maximum relative errors for simulated 
droplet temperature and skin surface temperature were $11.9 \%$ and $10.6 \%$. A slightly larger maximum relative error $(19.1 \%)$ in droplet diameter occurred near the nozzle exit, mainly because of the measurement uncertainty of PDPA due to the disturbance of the incompletely broken liquid block in the thick spray near the nozzle exit, and the absence of an accurate flashing atomization model for cryogens with low boiling points and high volatilities.

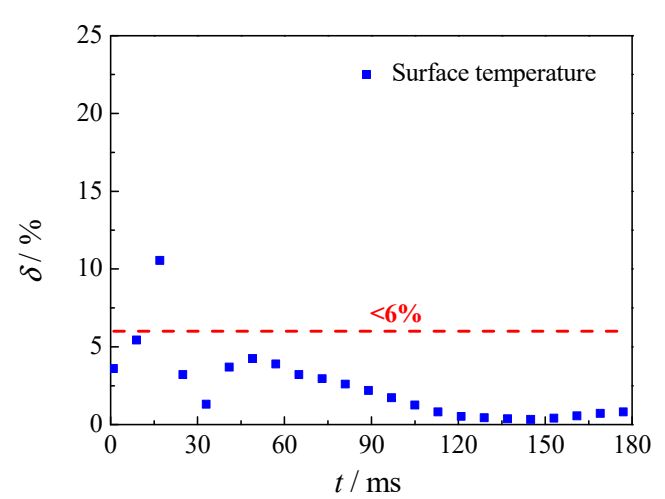

(a)

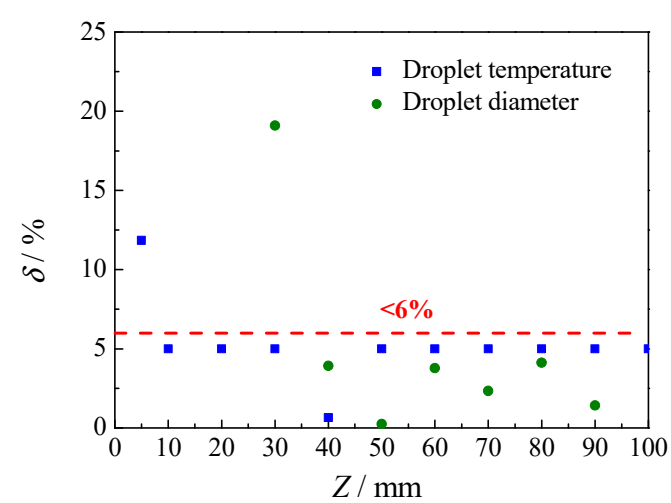

(b)

Figure 9. Relative errors between experimental and simulated results: (a) surface temperature of skin tissue and (b) droplet temperature and diameter.

\section{Results and Discussions}

The spray fields with R134a, R404A and R32 were compared in this study. Afterward, the spray distances with three cryogens were optimized, and the potential application of the new cryogen R32 in clinics was investigated. The spray durations to prevent cold injury were determined using the multi-scale heat transfer model for skin tissue frostbite, and the intervals between the CSC results with the three cryogens and laser irradiation were optimized by comprehensively considering cooling performance, cooling depth, cooling uniformity and risk of cold injury.

\subsection{Comparison of Spray Characteristics Using the Three Cryogens}

As depicted in Figure 10, R32 produced the lowest droplet temperature because of its lowest boiling point and highest latent heat. However, little differences were found in the spray pattern, which indicates that the cooling areas were similar for the same spray distances achieved by the three cryogens. The axial and radial distributions of spray are displayed in a 2D cloud pattern. As shown in Figure 11, core regions occurred in the R134a, R404A and R32 sprays, in which the droplet temperature was the lowest. The droplet temperature increases when axial and radial distance increase, owing to the enhanced convective heat transfer from warm air.

The spray characteristics (droplet temperature, Sauter mean diameter and axial velocity) obtained with R134a, R404A and R32 are drawn in Figure 12. The droplet temperature and Sauter mean diameter decreased as the axial distance increased, when $15 \mathrm{~mm}<\mathrm{Z} \leq 70 \mathrm{~mm}$, due to droplet evaporation. Afterward, the droplet temperature and Sauter mean diameter reached their minimum values and remained stable. In the initial evaporation period, the convective heat transferred from the ambient gas cannot supply enough heat induced by the extremely fast evaporation, leading to the rapidly decreasing droplet temperature because of the energy absorption from the remaining droplet liquid. Then, the droplet evaporation rate becomes smaller and smaller as the droplet temperature decreases, due to the decreasing molecular diffusion rate at the cryogen-air interface. Meanwhile, the convective heat transfer is enhanced because of the large temperature difference between the droplet and ambient gas, leading to the gradual reduction in droplet temperature. Finally, the droplet temperature reached its minimum value when the evaporation latent heat was counteracted by the convective heat transfer 
from the gas. Furthermore, compared with the R134a and R404A, a larger temperature reduction occurred with the R32 spray because of the more significant evaporation effect.

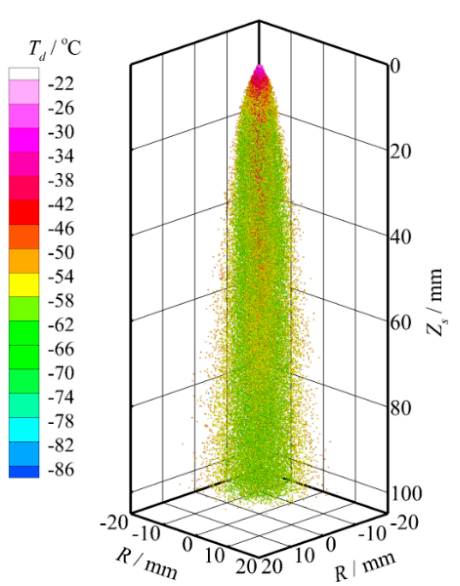

(a)

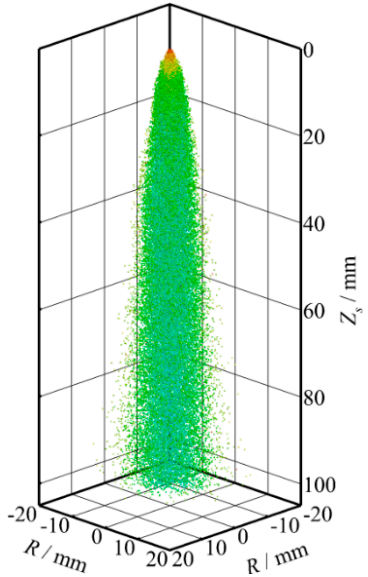

(b)

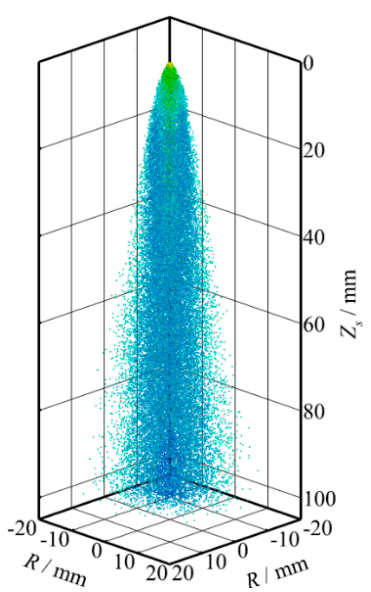

(c)

Figure 10. Comparison of 3D droplet temperature: (a) R134a, (b) R404A and (c) R32.

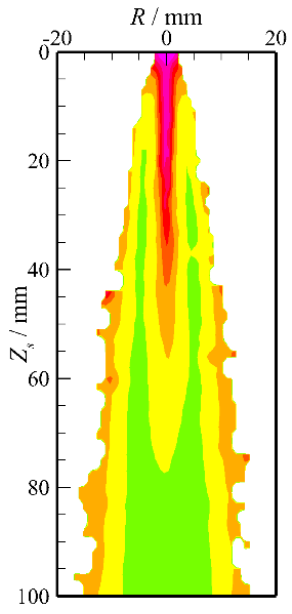

(a)

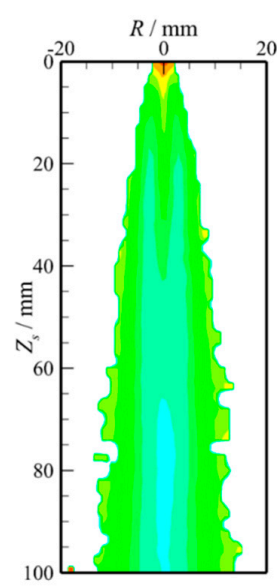

(b)

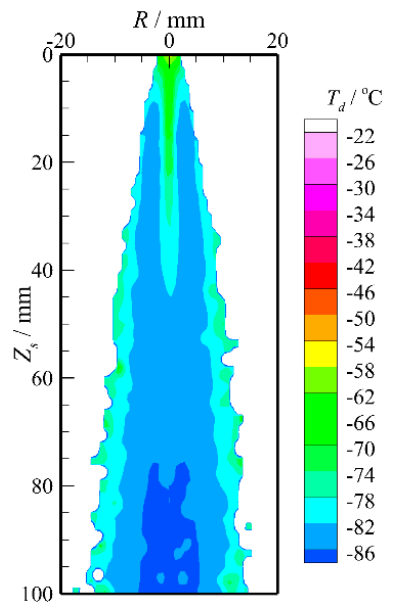

(c)

Figure 11. Comparison of droplet temperature distributions at axial section: (a) R134a, (b) R404A and (c) R32.

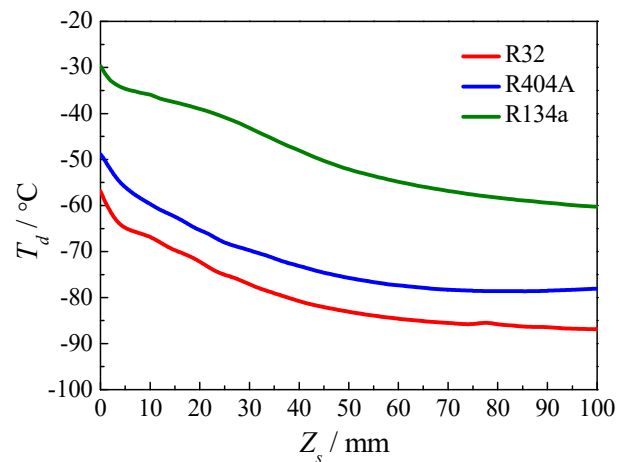

(a)

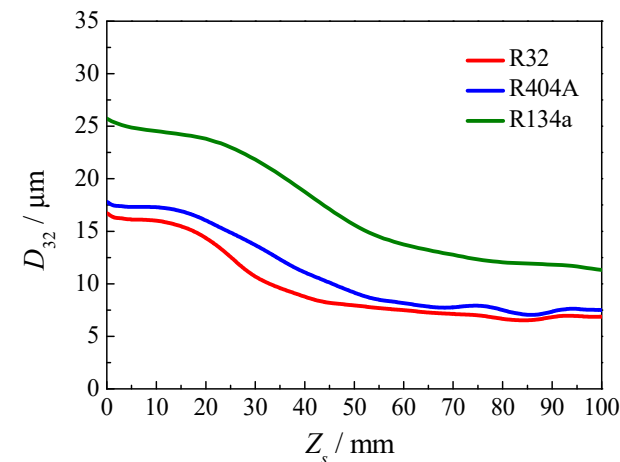

(b)

Figure 12. Comparison of the spray characteristics obtained using R134a, R404A and R32: (a) droplet temperature and (b) droplet Sauter mean diameter. 


\subsection{Optimization of Spray Distance}

Figure 13 demonstrates that the maximum heat flux $\left(q_{\max }\right)$ on the skin surface obtained using the three cryogens increased due to the droplet temperature reduction (Figure 12a). Afterwards, $q_{\max }$ reached the maximum value, and then decreased slowly because of the reduction in droplet impact kinetic energy caused by the decrease in droplet diameter and velocity. The $q_{\max }$ values of $\mathrm{R} 134 \mathrm{a}, \mathrm{R} 404 \mathrm{~A}$ and R32 achieved their respective peaks of $363.5,459.9$ and $603.6 \mathrm{~kW} \cdot \mathrm{m}^{-2}$ when the spray distances were 66.0, 43.1 and $22.5 \mathrm{~mm}$, respectively. R32 had the best cooling performance, whereas R134a had the lowest cooling capacity. The maximum surface heat flux for the R32 spray cooling was 1.66 and 1.31 times as large as that for R134 and R404A, respectively. The smallest optimum spray distance increased the cooling concentration, which was beneficial in order to accurately control the cooling for target.

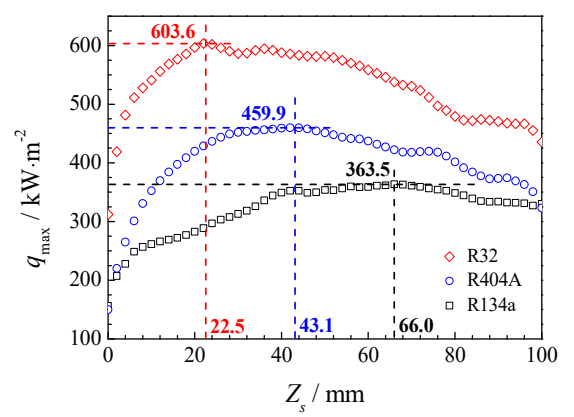

Figure 13. Variations in surface heat flux along axial spray distance.

As shown in Figure 14, the spatial and temporal surface heat flux distributions with R134a, R404A and R32 under their optimum spray distances exhibited considerable non-uniformity. The heat flux at the spray center initially increased, and then decreased with an increase in time, a result that was caused by a transient spray with a short spurt duration. The surface heat flux decreased gradually as the radial distance increased. Compared with R134a and R404A, R32 produced a larger surface heat flux and a smaller cooling area, thereby enhancing the cooling selectivity of the skin tissue. However, the large spatial and temporal non-uniformity of surface heat flux was detrimental to the uniform cooling of the skin tissue. Overall, R32 showed great clinical potential in CSC for the laser treatment of Ota's nevus due to its large cooling capability and low GWP.

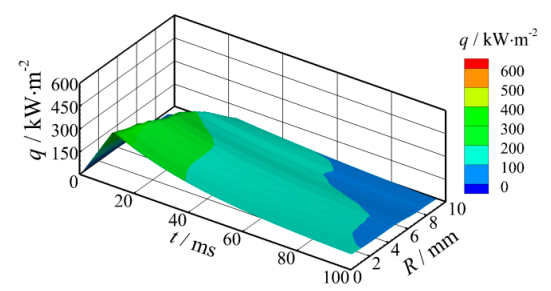

(a)

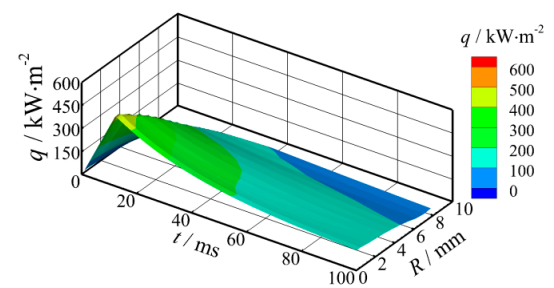

(b)

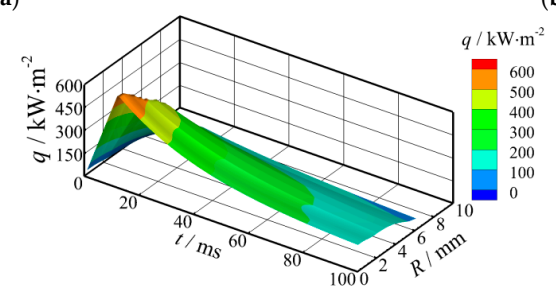

(c)

Figure 14. Spatial and temporal distributions of surface heat flux under optimum spray distance: (a) R134a, (b) R404A and (c) R32. 


\subsection{Temperature Distribution Inside Skin Tissue during CSC}

The temperature distributions in the central axis section inside the skin tissue during CSC under the optimum spray distance are shown in Figure 15. The surface temperature of the skin tissue decreased to the minimum value with R32 spray cooling, i.e., R32 produced the best cooling effect. However, the cooling depths achieved with R134a, R404A and R32 were almost identical $(300 \mu \mathrm{m})$ because of the small thermal conductivity of skin tissue.

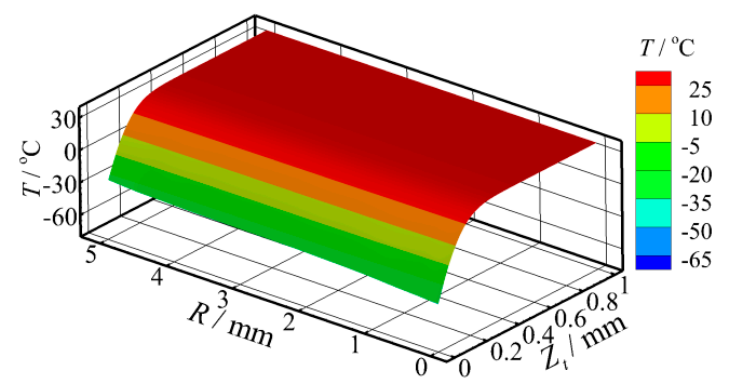

(a)

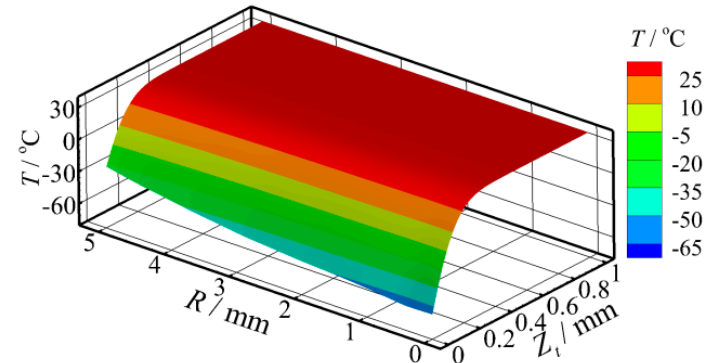

(b)

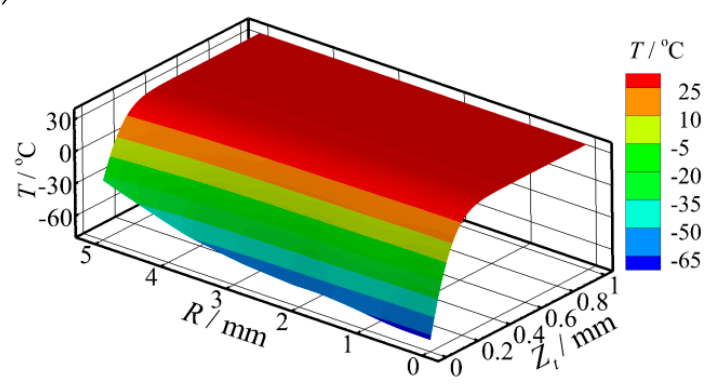

(c)

Figure 15. Temperature distributions at central axis section inside skin tissue during CSC under optimum spray distance: (a) R134a, (b) R404A and (c) R32.

Further detail on the cooling effect with the three cryogens can be found in Figure 16. The axial temperature increased with an increasing tissue depth. Compared with R134a and R404A, R32 spray cooling achieved the lowest tissue temperature, which allows for greater laser fluence and will improve the therapeutic effect. The tissue temperature further decreased when the cooling duration was extended.

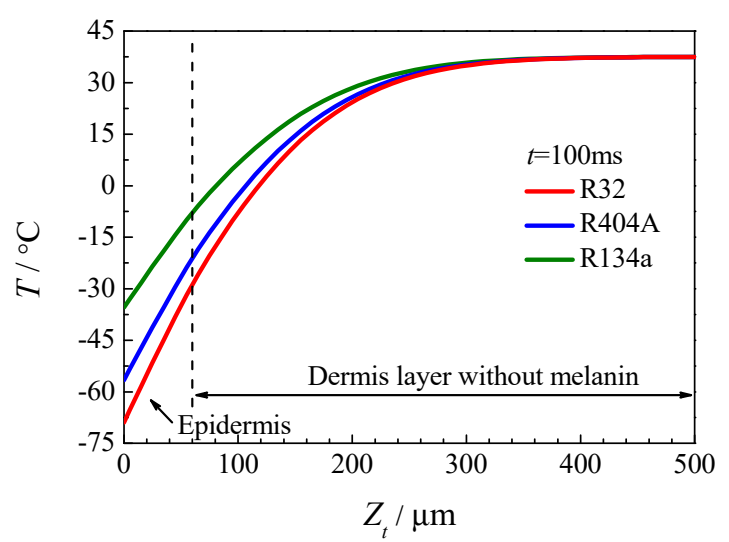

(a)

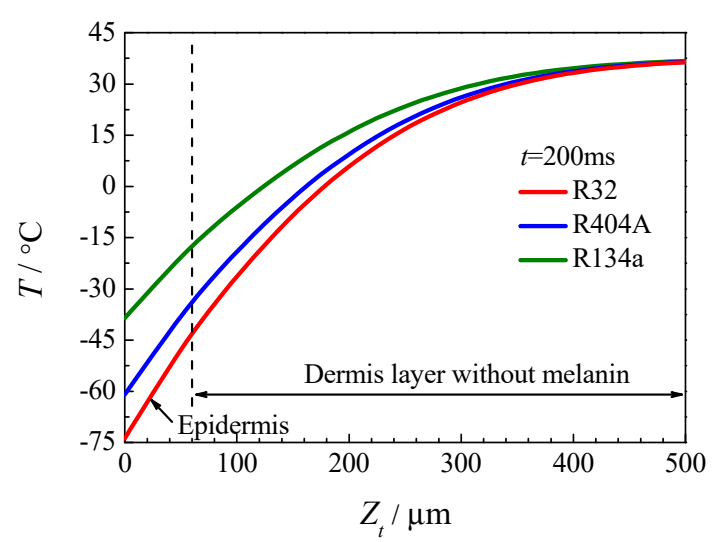

(b)

Figure 16. Comparison of axial temperature distribution inside skin tissue during CSC with three cryogens under optimum spray distance: (a) $t=100 \mathrm{~ms}$ and (b) $t=200 \mathrm{~ms}$. 


\subsection{Optimization of the Interval between CSC and Laser Irradiation}

In addition to cooling duration, cooling depth and uniformity are also affected by the time interval $(t)$ between CSC and laser irradiation. The best cooling effect can be obtained by simultaneously considering cooling depth and uniformity with cryogen R32 under the optimum spray distance. However, skin tissue suffers from cold injury with excessive cooling. Thus, $t$ should be determined by considering cooling depth, cooling uniformity, and risk of cold injury, which can be predicted by the multi-scale model.

Given that the diameter of the clinical laser spot is within $4 \mathrm{~mm}$, the radial surface temperature difference ( $\left.\Delta T=T_{r}=2 \mathrm{~mm}-T_{r}=0 \mathrm{~mm}\right)$ is defined to represent the cooling uniformity during CSC. As shown in Figure 17a, $\Delta T$ increased rapidly to the maximum value at $t=14$ and $35 \mathrm{~ms}$ with R404A, R32, and R134a. $\Delta T$ almost decreased to its minimum value $\left(6.1^{\circ} \mathrm{C}\right.$ with $\mathrm{R} 134 \mathrm{a}$, and $7.8^{\circ} \mathrm{C}$ with $\mathrm{R} 404 \mathrm{~A}$ and $\mathrm{R} 32)$ at $t=90 \mathrm{~ms}$ under CSC with the three cryogens. Compared with the cooling non-uniformity under R404A and R32, that under the R134a spray cooling was the smallest. According to the histological anatomy of Ota's nevus [37], melanin lesions are buried in the deep dermis (500 $\left.\mu \mathrm{m}<Z_{t} \leq 2000 \mu \mathrm{m}\right)$. The temperature distribution in the dermis with a melanin layer $\left(500 \mu \mathrm{m}<Z_{t} \leq 2000 \mu \mathrm{m}\right)$ should not be affected by CSC. Therefore, the cooling depth $\left(Z_{t, d}\right)$ should be controlled to less than $500 \mu \mathrm{m}$.

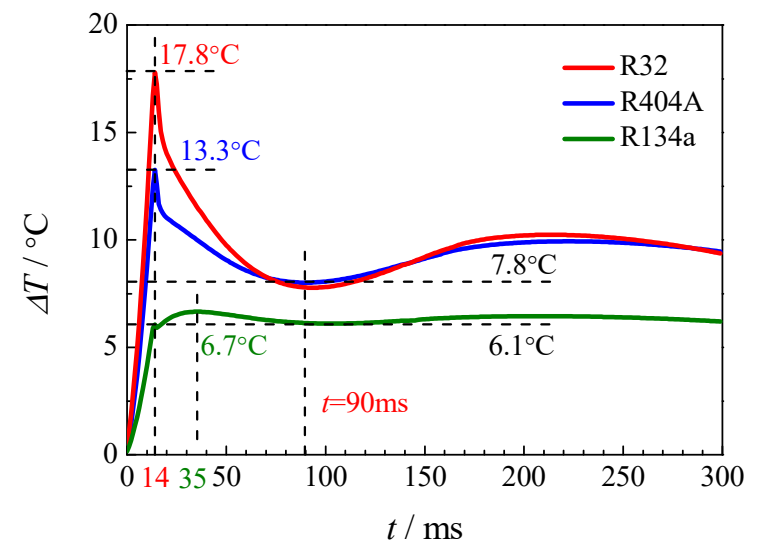

(a)

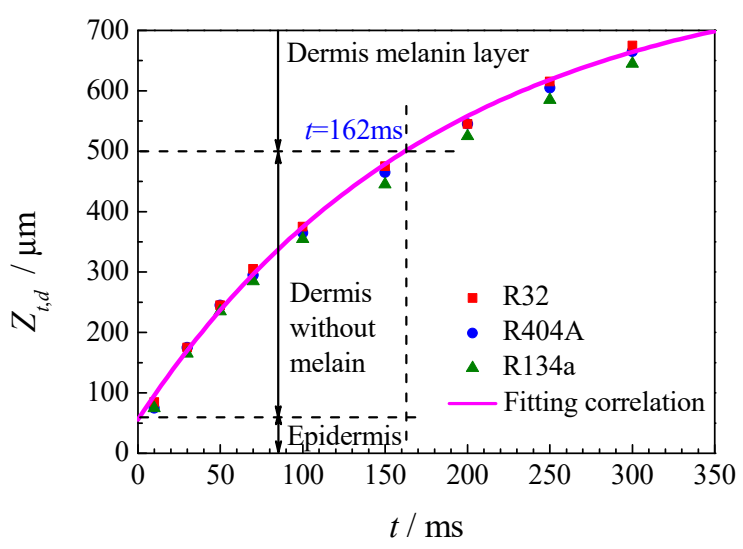

(b)

Figure 17. Time-varied (a) radial surface temperature difference and (b) axial cooling depth during CSC.

As shown in Figure $17 \mathrm{~b}$, the cooling depth increased as the cooling time increased. The $Z_{t, d}$ values under CSC with the three cryogens were almost identical. $t$ was determined to be $90-162 \mathrm{~ms}$ by considering cooling uniformity and cooling depth. The cooling depth with the function of cooling time was obtained with the least-squares method, as follows:

$$
Z_{t, d}=-752.56 \mathrm{e}^{-t / 181.81}+808.69
$$

The dynamic radius of the extra-cellular space $\left(R_{e c}\right)$ and the PIIF at the interface $\left(Z_{t}=60 \mu \mathrm{m}\right)$ between the epidermis and dermis are drawn in Figure 18 to evaluate the cold injury risk of skin tissue under CSC. As mentioned previously, cold injury occurs when the PIIF is 1 or $R_{e c}$ reaches its maximum value $\left(R_{e c, \max }\right)$. As illustrated in Figure $18 \mathrm{a}$, the $R_{e c}$ increased exponentially as the cooling duration increased. The $R_{e c}$ increased to its maximum values when $t=2.3,1.4$, and $1.1 \mathrm{~s}$ for R134a, R404A, and R32 spray cooling, respectively. $t$ should not exceed these durations for R134a, R404A, or R32 spray cooling to prevent the cold injury of skin tissue. Thus, a spray duration of $50 \mathrm{~ms}$ for clinical use can ensure the safety of CSC application. Under the spray duration of $50 \mathrm{~ms}$ and the optimum spray distance of $22.5 \mathrm{~mm}$, the radial surface temperature difference and cooling depth were determined to be $7.8^{\circ} \mathrm{C}$ and $354.8 \mu \mathrm{m}$, when the interval between CSC and laser irradiation was $40 \mathrm{~ms}$. 


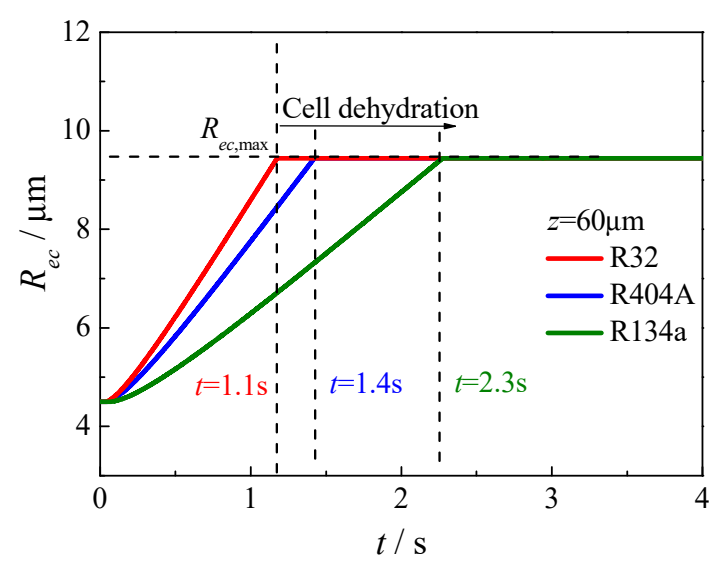

(a)

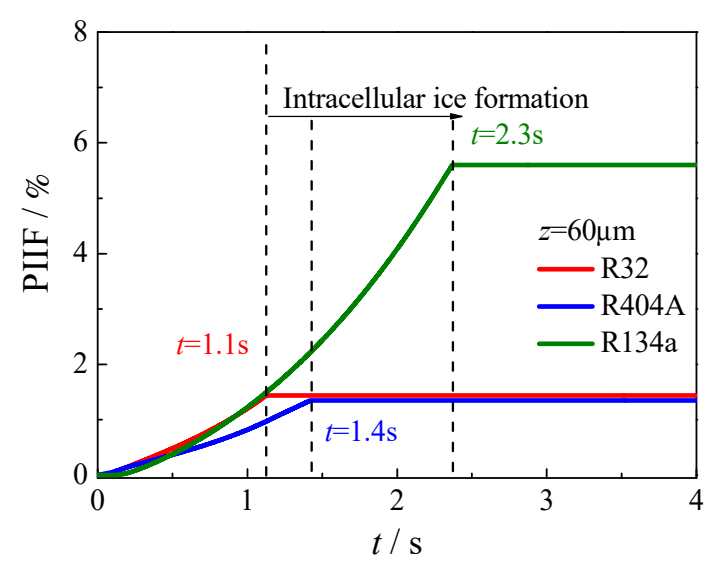

(b)

Figure 18. Time-varied (a) radius of extra-cellular space and (b) probability of IIF during CSC.

The PIIF values under CSC with the three cryogens are depicted in Figure 18b. The variations in the PIIFs were similar to those of $R_{e c}$. However, the PIIFs were less than $6 \%$ owing to the low thermal conductivity of skin tissue. Although the surface temperature decreased rapidly upon the subcooling droplet's impact on the skin surface, the temperature inside the skin tissue decreased gradually, suggesting that the cold injury under CSC was dominated by cell dehydration. Moreover, the PIIFs when cold injury occurred were $5.6 \%, 1.4 \%$ and $1.3 \%$ for R134a, R404A, and R32 spray cooling, respectively, indicating that CSC entailed a very low possibility of IIF. According to cellular frostbite theory, PIIF has a positive correlation with the effective cell superficial area $(A)$ for water transport and integral time $(t)$. The high cell dehydration rates induced by R404A and R32 spray cooling, with good cooling capability (i.e., lower cell temperature), produced a small $A$, leading to a small PIIF for skin frostbite with the R404A and R32 sprays. In consideration of the cooling effect, depth and uniformity, and the risk of cold injury, $t$ was optimized as $90-162 \mathrm{~ms}$ for the three cryogens.

\section{Conclusions}

In this work, an accurate, efficient, complete simulation system that considers the entire cryogen spray cooling of gas-liquid flow in the capillary tube, the atomization, evaporation and breakup of spray droplets, and the phase-change heat transfer (cold injury) inside the bio-tissue, were established and validated. The spray characteristics in terms of droplet temperature and diameter, and the heat transfer performance on the skin surface during CSC with R134a, R404A, and R32, were compared. The temperature distributions and cold injury inside the skin tissue were simulated using the multi-scale heat transfer model based on cellular frostbite theory to evaluate the cooling effect during CSC quantitatively.

During spraying, the droplet temperature and Sauter mean diameter decreased exponentially along the axial distance because of droplet evaporation. R32 produced the lowest droplet temperature, the smallest droplet diameter, and the lowest skin tissue temperature, owing to its lowest boiling point and highest latent heat among the three cryogens. This result indicates that R32 had the best cooling capability. The maximum surface heat fluxes of R134a, R404A and R32 were respectively optimized at $363.5,459.9$ and $603.6 \mathrm{~kW} \cdot \mathrm{m}^{-2}$, at spray distances of $66.0,43.1$ and $22.5 \mathrm{~mm}$, respectively. The maximum surface heat flux under R32 spray cooling was 1.66 and 1.31 times as large as the values under R134a and R404A. Moreover, the smallest optimum spray distance of R32 spray cooling increased the cooling concentration, which was beneficial for the accurate cooling of skin. Given its low GWP, the environmentally friendly R32 has excellent potential as a clinical CSC technique in the laser treatment of Ota's nevus, in terms of cooling capability and control of the cooling area.

The risk of cold injury in skin tissue was evaluated by considering cell dehydration and IIF simultaneously. The low probability $(<6 \%)$ of IIF under CSC indicates that the cold injury in the 
skin tissue was dominated by cell dehydration, because of the low heat conductivity of skin tissue. To prevent cold injury, the intervals between CSC and laser irradiation should not exceed 2.3, 1.4 and $1.1 \mathrm{~s}$ for R134a, R404A and R32 spray cooling, respectively. Thus, a spray duration of $50 \mathrm{~ms}$ in clinical use can ensure the safety of CSC application. Considering the cooling effect, depth and uniformity, and the risk of cold injury, the interval between CSC with the three cryogens and laser irradiation was determined to be $90-162 \mathrm{~ms}$.

Author Contributions: Conceptualization, J.T. and B.C.; methodology, J.T. and Z.Z.; software, D.L.; validation, J.T. and Z.Z.; investigation, J.T.; writing —original draft preparation, J.T.; writing—review and editing, B.C.; funding acquisition, B.C. All authors have read and agreed to the published version of the manuscript.

Funding: This research was founded by the Natural Science Foundation of China [52036007].

Conflicts of Interest: The authors declare there is no conflict of interest.

\section{Nomenclature}

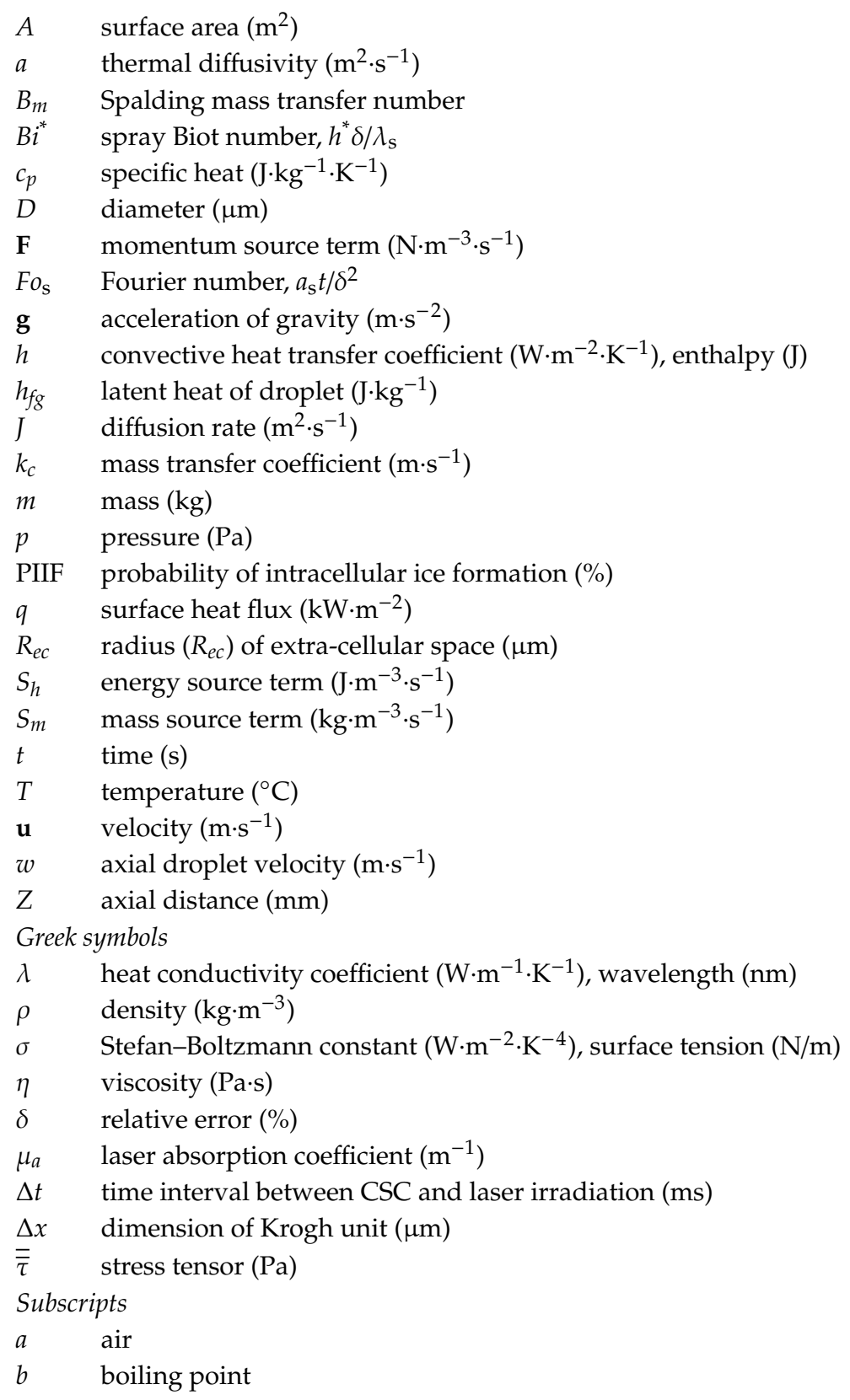




$\begin{array}{ll}c & \text { cell } \\ d & \text { droplet } \\ f & \text { intracellular water } \\ i & \text { component } \\ \text { max } & \text { maximum value } \\ n s & \text { Krogh unit } \\ r & \text { radiation } \\ s & \text { spray } \\ \text { sat } & \text { saturation } \\ t & \text { skin tissue } \\ 0 & \text { initial value }\end{array}$

\section{References}

1. Choi, J.E.; Lee, J.B.; Park, K.B.; Kim, B.S.; Yeo, U.C.; Huh, C.H.; Kim, J.H.; Kye, Y.C. A retrospective analysis of the clinical efficacies of Q-switched Alexandrite and Q-switched Nd:YAG lasers in the treatment of nevus of Ota in Korean patients. J. Dermatol. Treat. 2015, 26, 240-245. [CrossRef] [PubMed]

2. Hirayama, T.; Suzuki, T. A New Classification of Ota's Nevus Based on Histopathological Features. Dermatology 1991, 183, 169-172. [CrossRef] [PubMed]

3. He, L.; Zou, Y.-L.; Zhang, L.; Liu, L. The Clinical and Histopathologicl Analysis of Zygomaticofacial Naevus Fuscoceruleus, Naevus of Ota and Melasma. Chin. J. Derm. 2003, 17, 25-29.

4. Anderson, R.R.; Parrish, J.A. Selective photothermolysis: Precise microsurgery by selective absorption of pulsed radiation. Science 1983, 220, 524-527. [CrossRef]

5. MP, G. Cutaneous and Cosmetic Laser Surgery; Elsevier: Maryland Heights, MO, USA, 2006.

6. Aguilar, G. Dynamics of cryogen deposition relative to heat extraction rate during cryogen spray cooling. Proc. SPIE 2000, 3907, 37-48. [CrossRef]

7. Nelson, J.S.; Milner, T.E.; Anvari, B.; Tanenbaum, B.S.; Kimel, S.; Svaasand, L.O.; Jacques, S.L. Dynamic epidermal cooling during pulsed laser treatment of port-wine stain. A new methodology with preliminary clinical evaluation. Arch. Dermatol. 2016, 131, 695-700. [CrossRef]

8. Dai, T.; Yaseen, M.A.; Diagaradjane, P.; Chang, D.W.; Anvari, B. Comparative study of cryogen spray cooling with R-134a and R-404a: Implications for laser treatment of dark human skin. J. Biomed. Opt. 2006, 11. [CrossRef]

9. Zhou, Z.-F.; Chen, B.; Wang, R.; Wang, G.-X. Comparative investigation on the spray characteristics and heat transfer dynamics of pulsed spray cooling with volatile cryogens. Exp. Therm. Fluid Sci. 2017, 82, 189-197. [CrossRef]

10. Tian, J.M.; Chen, B.; Li, D.; Zhou, Z.F. Transient spray cooling: Similarity of dynamic heat flux for different cryogens, nozzles and substrates. Int. J. Heat Mass Transf. 2017, 108, 561-571. [CrossRef]

11. Dossat, R.J. Principles of Refrigeration; Prentice Hall: Englewood Cliffs, NJ, USA, 1991.

12. No, E.J. Available online: http://www.ilo.org/dyn/cisdoc2/cismain.details?p_lang=en\&p_doc_id=68628 (accessed on 28 May 2020).

13. Aguilar, G.; Wang, G.X.; Nelson, J.S. Dynamic behavior of cryogen spray cooling: Effects of spurt duration and spray distance. Lasers Surg. Med. 2003, 32, 152-159. [CrossRef]

14. Refrigerants—Designation and Safety Classification; ISO 817: 2014; ISO: Geneva, Switzerland, 2014.

15. Aguilar, G.; Svaasand, L.O.; Nelson, J.S. Effects of hypobaric pressure on human skin: Feasibility study for port wine stain laser therapy (Part I). Lasers Surg. Med. 2005, 36, 124-129. [CrossRef]

16. Norvang Nilsen, L.; Fiskerstrand, E.; Nelson, J.S.; Berns, M.; Svaasand, L. Epidermal Melanin Absorption in Human Skin; SPIE: Bellingham, WA, USA, 1996; Volume 2624.

17. Wen-Lin, Y.U.; Dong, Z.; Qin, L.; Kai-Hua, Y.; Chun-Li, L. Virtual instrumentation technique and its application in skin spectrum detecting system. Chin. J. Aesthetic Med. 2007, 55, 34. [CrossRef]

18. Chen, B.; Tian, J.; Wang, R.; Zhou, Z. Theoretical study of cryogen spray cooling with R134a, R404A and R1234yf: Comparison and clinical potential application. Appl. Therm. Eng. 2019, 148, 1058-1067. [CrossRef]

19. Nilpueng, K.; Wongwises, S. Numerical simulation of refrigerants flowing through short-tube orifices during flashing process. Hvac R Res. 2013, 19, 159-174. [CrossRef] 
20. Zeng, Y.; Lee, C.-F. Modeling of Atomization Under Flash Boiling Conditions. J. Korean Soc. Combust. 2002, 7, 44-51.

21. Witlox, H.; Harper, M.; Bowen, P.; Cleary, V. Flashing liquid jets and two-phase droplet dispersion: II. Comparison and validation of droplet size and rainout formulations. J. Hazard. Mater. 2007, 142, 797-809. [CrossRef] [PubMed]

22. Witlox, H.W.M.; Harper, M.; Oke, A.; Bowen, P.J.; Kay, P. Sub-cooled and flashing liquid jets and droplet dispersion I. Overview and model implementation/validation. J. Loss Prev. Process Indust. 2010, 23, 831-842. [CrossRef]

23. Ashgriz, N. Handbook of Atomization and Sprays: Theory and Applications; Springer: Berlin/Heidelberg, Germany, 2011.

24. Ranz, W.E.; Marshall, W.R. Evaporation from Droplets: Part I and II. Chem. Eng. Prog. 1952, 48, 141-173.

25. Sirignano, W.A. Fluid Dynamics and Transport of Droplets and Sprays; Cambridge University Press: Cambridge, UK, 1999.

26. Zhou, Z.; Wang, G.; Chen, B.; Guo, L.; Wang, Y. Evaluation of Evaporation Models for Single Moving Droplet with a High Evaporation Rate. Powder Technol. 2013, 240, 95-102. [CrossRef]

27. Taylor, G.I. The Shape and Acceleration of a Drop in a High Speed Air Stream. Sci. Pap. GI Taylor 1963, 3, 457-464.

28. Reitz, R.D. Modeling atomization processes in high-pressure vaporizing sprays. At. Spray Technol. 1987, 3, 309-337. [CrossRef]

29. Beale, J.C.; Reitz, R.D. Modeling Spray Atomization with the Kelvin-Helmholtz/Rayleigh Taylor Hybrid Model. At. Sprays 1999, 9, 623-650. [CrossRef]

30. Apte, S.V.; Gorokhovski, M.; Moin, P. LES of atomizing spray with stochastic modeling of secondary breakup. Int. J. Multiph. Flow 2003, 29, 1503-1522. [CrossRef]

31. Li, D.; Chen, B.; Wu, W.J.; Wang, G.X.; He, Y.L. Multi-scale modeling of tissue freezing during cryogen spray cooling with R134a, R407c and R404a. Appl. Therm. Eng. 2014, 73, 1489-1500. [CrossRef]

32. Morsi, S.A.; Alexander, A.J. An investigation of particle trajectories in two-phase flow systems. J. Fluid Mech. 2006, 55, 193-208. [CrossRef]

33. Miller, R.S.; Harstad, K.; Bellan, J. Evaluation of equilibrium and non-equilibrium evaporation models for many-droplet gas-liquid flow simulations. Int. J. Multiph. Flow 1998, 24, 1025-1055. [CrossRef]

34. Sazhin, S.S. Advanced models of fuel droplet heating and evaporation. Prog. Energy Combust. Sci. 2006, 32, 162-214. [CrossRef]

35. Toner, M.; Cravalho, E.G.; Karel, M. Thermodynamics and kinetics of intracellular ice formation during freezing of biological cells. J. Appl. Phys. 1990, 67, 1582-1593. [CrossRef]

36. Bischof, J.C.; Rubinsky, B. Microscale Heat and Mass Transfer of Vascular and Intracellular Freezing in the Liver. J. Heat Transf. 1993, 115, 1029-1035. [CrossRef]

37. Kang, W.H.; Lee, E.S.; Choi, G.S. Treatment of Ota's nevus by Q-switched alexandrite laser: Therapeutic outcome in relation to clinical and histopathological findings. Eur. J. Dermatol. EJD 2000, 9, 639-643.

38. Zhou, Z.; Chen, B.; Wang, Y.; Guo, L.; Wang, G. An experimental study on pulsed spray cooling with refrigerant R-404a in laser surgery. Appl. Therm. Eng. 2012, 39, 29-36. [CrossRef]

39. Aguilar, G.; Díaz, S.H.; Lavernia, E.J.; Nelson, J.S. Cryogen spray cooling efficiency: Improvement of port wine stain laser therapy through multiple-intermittent cryogen spurts and laser pulses. Lasers Surg. Med. 2002, 31, 27-35. [CrossRef]

40. Zhou, Z.; Wu, W.; Chen, B.; Wang, G.; Guo, L. An experimental study on the spray and thermal characteristics of R134a two-phase flashing spray. Int. J. Heat Mass Transf. 2012, 55, 4460-4468. [CrossRef]

Publisher's Note: MDPI stays neutral with regard to jurisdictional claims in published maps and institutional affiliations. 